\title{
An E-Learning Experience: A written analysis based on my experience with primary school teachers in an e-Learning pilot project
}

\author{
Kabita Bose \\ University of Botswana
}

\begin{abstract}
This article reports the experience of an e-Learning pilot project selected by the Educational Technology Unit (EduTech) of the Centre for Academic Development (CAD), University of Botswana (UB). This e-Learning package was designed and delivered in connection with the three-credit course "Issues and Trends in Early Childhood Education" (EPI-642), which is required for the first year of the master's program in the Department of Primary Education. The course was taught via a flexi-time, gradual, phase-by-phase transition from traditional face-toface teaching to the electronic medium of an e-Learning lab (called SMART classroom). This course utilized a student centred e-Learning package that retained the learning qualities of traditional teaching, personal guidance, and mentoring, while seeking to enhance students' research and computer skills.
\end{abstract}

E-Learning is "the use of Internet and digital technologies to create experiences that educate fellow human beings" (Horton, 2001). E-Learning was born during the dot-com frenzy, and the term "e-Learning" was not well known until a few years ago. But now the term is common, especially in the University community. In 1999, more than 50 percent of US college students were planning to have Internet access from their dormitory rooms, and virtually all were planning to have access from campus locations. Today, more than 90 percent of students have accessed Internet, with 50 percent accessing Web daily, and nearly 40 percent of all college courses using Internet resources (OECD, 2001).

As a network technology, the Internet creates, fosters, delivers, and facilitates learning, anytime and anywhere. In distant modes of education, it provides connections to outside computers (Wheeler, 2003). Network technologies also make possible delivery of individualized, comprehensive, dynamic learning content in real time, aiding in the development of knowledge communities. By making them accountable and accessible, it links learners and practitioners with experts and enables people and organizations to keep apace with the rapid changes that define the Internet world. It is a force that gives people and organizations the competitive edge, permitting them to participate in the rapidly changing global economy (elearning.com, 2002). Clearly, the penetration of Internet in the post-secondary sector is significant. 
Bose An E-Learning Experience:

A written analysis based on my experience with primary school teachers in an e-Learning pilot project

An initiative was undertaken to introduce e-Learning at the University of Botswana (UB), where e-Learning was defined as "The appropriate organisation of information and communication technologies, for advancing student-oriented, active, open, and life-long teaching-learning processes” (Thurab-Nkhosi, 2003). With this guiding principle for e-Learning in hand, UB's Centre for Academic Development (CAD) invited proposals from different faculties and departments to conduct a pilot study in December 2002. The author of this article submitted a proposal for design and delivery of a three credit course "Issues and Trends in Early Childhood Education" to first year Department of Primary Education Masters' students using an e-Learning approach. The course was approved and a development team lead by the author, who was also the content expert, was established. The course was developed collaboratively by the entire team, after which the author acted as the instructor and the moderator of the e-Learning component of the course. The course was delivered successfully in January to May 2003.

Resources used for the development of this e-Learning package were all an integral part of the University's EduTech, Centre for Academic Development, and contributions to this development were a part of the EduTech's regular activities; all content development aspects of this course was undertaken by the University's Department of Primary Education. The only additional resource required was a research assistant, employed for a total of 40 hours at a cost of Botswana Pula 1850 , which is equivalent to US $\$ 370$.

\section{Purpose of The E-Learning Course}

\section{A Flexi-Time Approach}

An e-Learning course offers a flexible time and location approach by changing the learning environment. It enables learning to take place in a variety of different places, both physical and virtual. Learners now have a choice and as a result increasingly wish to combine the options, choosing when and where they study and learn. For education providers, preparation and integration of materials and services have now become a challenge, because it fundamentally changes the learning environment (OECD, 2001, p. 22).

Students who work full time and have tight work schedules, who have young children, or are disabled, or for whatever reason are unable to attend regular classes at a specific time and location, often require and really appreciate a flexible time and location course. But to be successful, such courses require self-motivated and independent learners (Mantyla and Woods, 2001).

In this project, most learners in the target group were part-time UB students. They were full-time working professionals (i.e., primary school teachers living in the outskirts of Gaborone City, Botswana) who travelled anywhere from 30 to 60 kilometres from their schools to attend classes held the University. Classes could only be held in the afternoon and/ or evening, after work/ school hours. Many students were also mothers and who had to look after their families. Thus it was determined that a flexi-time e-Learning course would enable the delivery of the course material at students' work place, home, cyber café, or at campus, making it easy and convenient for primary level teachers who now must carry out lifelong learning concurrently with their normal workload and personal obligations. 
Bose An E-Learning Experience:

A written analysis based on my experience with primary school teachers in an e-Learning pilot project

\section{A Mixed-Mode, Blended Approach}

E-Learning was misinterpreted after it was first introduced. It was oversimplified and wildly optimistic. Some described e-Learning as putting all learning on computers. They felt that eLearning could result in savings in instructor salaries, and could keep students out of the classroom. They felt students could learn anywhere, whenever they wanted, and could save time by studying only what they needed, and could learn at an optimal pace, neither to be held back nor bypassed by the rest of the class. But they forgot that learning is a social experience. Even in the classroom much learning takes place informally in exchanges between students. Most people learn better when computer-mediated lessons are combined with virtual classes, study groups, team exercises, mentors and help desks, off-line events, and online coaches. The act of learning itself has not changed. Computers can make aspects of learning more convenient, but they do not eliminate the need for human intervention. The presumption that e-Learning would automate every aspect of learning sounds unnatural and is unnatural (How People Learn, 2003).

Thus a mixture of both face-to-face and distance mode was thought to be most appropriate for the target group. In fact, all conventional universities are becoming mixed-mode where a convergence of distance education and conventional education is becoming apparent. Dual mode institutions are emerging in many countries, and the distinction between traditional and distant mode is disappearing. Institutions are being replaced by "mixed-mode" education systems, which are substantively centred on communication and technology (OECD, 2001).

\section{A Student-Centred Approach}

An e-Learning package not only provides a marriage of Internet, digital technology, and learning, it also facilitates student/ learner centred learning. In recent years, there has been a shift from the teacher/ instructor-centred approach to a student-centred approach. A teacher-centred approach believes in teachers disseminating and pouring content into empty heads as students passively listen, rather than proactively engaging with what is incoming and what is already there. With this approach, students usually recite, often by rote memory, some concepts on examination scripts. In this form of instruction, teachers are seen as the "gatekeeper" of knowledge, which is acquired from textbooks. However, teacher-centred, textbook-based learning is not conducive to our ever changing information rich, global society. This situation is well put by Cook and Cook (1998) who said: "Rapidly changing political, social, and economic environments often made textbooks and articles outdated soon after they are published" (p.1).

In an extreme situation of the teacher-centred approach, students never learn how to find out the right information, or how to discover and learn to use higher-level thinking skills such as analysis, synthesis, and evaluation to disseminate information to others. On the contrary, a student/ learner-centred approach believes that students are active participants and construct their own knowledge by interacting with the information available. Such an approach believes in rewiring the brain by sculpting new pigeonholes and adding new connections. It places students at the centre of the teaching/ learning process, and believes that teachers should act as mentors, navigators, facilitators, or "guides" to help students access, organize, construct, and transfer information to solve authentic problems. According to Harmon and Hirumi (1996) "Studentcentred learning is where students work in both groups and individually to explore problems and become active knowledge workers rather than passive knowledge recipients” (p. 1). 
Bose An E-Learning Experience:

A written analysis based on my experience with primary school teachers in an e-Learning pilot project

In this approach, students gain expertise not only in the content area being studied, but also in learning process itself - i.e., how to learn through discovery, inquiry, and problem solving. Thus it was felt that a student-centred e-Learning package would be appropriate for the UB target group.

\section{ICT Empowerment}

E-Learning generally promotes greater proficiency in Information Technology (IT) skills, which helps in personal employability and corporate competitiveness (Stephenson, 2001). The world is changing towards an Information age - and Botswana does not want to be left behind, a fact that is clearly articulated in the government's Vision 2016 (2000), which states: "Botswana must recognise the importance of information and of developing efficient information systems and networks for the support of research, education, development and communication with the rest of the world" (p.20).

This aim can only be realised, however, by educating the nation's people about the importance and use of technology by facilitating Information and Communication Technology (ICT) empowerment. Use of ICT can be of great help in this regard. As it is stated in (OECD, 2001):

ICT can empower the learner by offering choice and potentially more engaging and effective means of learning. ICT can accommodate a whole range of different learning styles and preferences. Individuals differ markedly in their appreciation for ability to learn from different types of communications, learning processes and materials. Interactive multimedia and the opportunity to combine various media resources, styles and methods is a key feature of ICT-enabled learning (p.23).

An e-Learning course, which requires a repeated use of ICT resources like computers, floppy discs, printers, multimedia projectors, Internet connections, email and discussion forums to send, retrieve, and process information, ultimately empowers students via the development of their computing skills. After all, the only way to learn a skill is to practice it. A student may not have any interest in how a system works, but might be interested in knowing how to use it to receive information. Moreover, the essence of real education is repeated practice (Schank, 2002). The author was thus interested to establish the best practices required to create high quality e-Learning packages, since this would not only cover the important issues of the subject area, but also enhance students' basic computer skills through repeated use of computer resources.

\section{Enhancement of Research Skills}

A key component in an e-Learning approach is students' ability to obtain information and research materials (Lynch, 2002). The author determined that an e-Learning course, with Internet access to online materials with hyperlinks to relevant websites, would encourage students to actively participate in the search for materials and answers, active learning that would enhance their research skills.

To optimise resource management through interaction, counselling, coaching, assessment, and evaluation, the author determined that it would be beneficial to establish a phase-by-phase, student-centred, flexi-time course. She also felt that UB would be able to make better use of its resources in terms physical place and human resources, as well as regularly update the course to 
Bose An E-Learning Experience:

A written analysis based on my experience with primary school teachers in an e-Learning pilot project

take advantage of technological advances and development, and to deliver newly digitised course materials. The author also felt that the propagation of such courses would increase the market opportunities for the ICT industry in terms of hardware, software, and related services such as Internet Service Providers (ISPs). Thus a phase-by-phase, mix-mode/ blended e-Learning course, that strived to be individualistic, flexible, competency-based, and varied in methodology - as well as unconstrained by time or place - was proposed for the target group at UB. The plan was to achieve this objective through the use of a variety of instructional tools and methods, as well as flexible learning arrangements in terms of time and place. The course evolved and was ultimately delivered in three phases using a combination of face-to-face and independent/ online learning.

\section{Course Design}

"Issues and Trends in Early Childhood Education" (EPI642) was a three-credit course. UB students enrolled in this course were required to devote at least three hours per week. The Course Outline was as follows:

1. Early Childhood Education

2. Historical Perspectives of Early Childhood Education

3. Theories of Early Childhood Education

4. School, Community, and Home Resources

5. Current Trends and Issues in Early Childhood Education

6. Research Relevant to Early Childhood Education

The objectives of the proposed e-Learning course were to:

1. Provide students' the basic course contents

2. Provide students' a flexi-time course

3. Provide students a mixed-mode/ blended course in phases

4. Provide student-centred teaching/ learning processes

5. Provide ICT empowerment to students

6. Provide instruction to enhance students’ research skills

The objectives of the basic contents of the course were formulated.

\section{Course Development}

"The most effective e-Learning, whether it is delivered as an e-Learning solution or conventional face to face instruction, occurs as a result of careful planning derived from the needs of the organisation and learner" (Syrtis.com, 2001, p.1). This statement articulates how it is important to 
Bose An E-Learning Experience:

A written analysis based on my experience with primary school teachers in an e-Learning pilot project

design a course systematically. In the present project an attempt was made to design the course systematically. Once the course was approved, an EduTech team was formed which consisted of the following members:

1. Project leader/ Content Expert/ Author

2. Instructional Designer

3. Graphic Designer

4. Library Representative

5. Editor

6. Research Assistant

7. Research Project Leader

The team worked in a collaborative manner to develop the course, and the project leader received constant support from the instructional designer to develop the course structure, create the course webpages, and upload them on WebCT. It was a rich learning experience for all involved. The project leader underwent training and learned techniques involved in creating the structure of a webpage, creating a hypertext mark-up language (HTML) page by using FrontPage software, and in uploading these webpages to the WebCT platform. This learning experience will no doubt greatly help in developing future e-Learning courses.

A rough course schedule and a curriculum/ topic structure were developed. The structure of the website was finalised, which actually determined the structure of individual webpages and subject areas. The proposed structure consisted of a homepage with icons for establishing links to the course outline, schedule, content, email, discussion board, and research.

All webpage content was created in-house. Also, with the assistance of the research assistant and library representative, the content expert searched and extracted the right list of readings, list of relevant website links, handouts, and presentation materials. The instructional material was generated electronically by using ICT resources. The created material was then converted to HTML and uploaded to the WebCT platform with the help of the instructional designer. The eLearning package developed was hosted on the WebCT platform housed on the UB server. The graphic designer provided the logo and Icons, which made the WebCT course look truly striking indeed. Finally, and most importantly, course material contents were regularly updated.

\section{Course Implementation}

After the e-Learning course was launched, students met at the SMART classroom (e-Learning lab) of EduTech, Centre for Academic Development. The SMART classroom was comprised of numerous computers with a WebCT platform. The instructor also had access to a multimedia projector for delivering the required material. In sum, the lab had every facility that could be required by both students and instructor.

The course consisted of six modules and was delivered in three phases. A mixed-mode, blended course approach was used. There was a gradual shift from teaching face-to-face to online 
Bose An E-Learning Experience:

A written analysis based on my experience with primary school teachers in an e-Learning pilot project

presentations using WebCT tools. In the first phase, face-to-face contact occurred three hours per week. During the second phase, face-to-face contact was reduced to two hours per week, and by the third phase it was further reduced to one hour only. Because students were curious to use the online material, the first phase took place in one session. The second phase continued for approximately eight sessions, and the third phase continued for three. Each session was a blend of face-to-face and online teaching. Using a PowerPoint presentation projected by a multi-media projector, the instructor guided the students who spent first part of the session face-to-face accessing course materials online, while discussing and receiving the summarised version of the course module. After summarising the course content, the instructor uploaded the PowerPoint presentation to the WebCT platform for students' to access. The second part of the session was then spent making preparations for the next classroom presentation. This was achieved both faceto-face and online. During second and third phase, students accessed course materials and made preparations mainly online, either during class time or at a time convenient to them. As such, preparatory materials like references, website links, and handouts were provided to students via the WebCT platform.

Students engaged in an orientation course during the first session, at which time they were given an Internet account, which was password protected to access the course materials from any Internet resource available. They also received special training on how to use WebCT platform, how to use diskettes to copy and print, and how to access the course information online. On the first day, some students could not even hold the mouse, so the author spent extra time and effort to bolster students' enthusiasm and motivate them to use computer effectively.

Communication between teacher and students through the use of a discussion forum was an important aspect of this course; the discussion forum contained links to learning event information, announcements, and questions (Jolliffee, Ritter, and Stevens, 2001). During the second and third phase, students participated in online discussions and made comments on the issues that were ultimately posted on the discussion forum.

Because email can be effectively used inform students about activities, grades, and reminders on upcoming events, the instructor's use of email was a central to efficiently conducting the course (Stephenson, 2001). In this project, students sent email to the author. The author was also in regular email contact with students (e.g., sending assignments, grades, making announcements, responding to queries, etc).

The design of this course encouraged students to participate in active research. As such, a sizable amount of personal tutoring took place along with face-to-face teaching. Students searched relevant materials, made copies on the floppies, printed documents, and used the materials they gathered and synthesised in classroom presentations. Towards the conclusion of the third phase, students indicated that they felt quite confident working with the Internet without assistance.

Employing a student centred approach the instructor evaluated the students' progress towards the achievement of learning objectives, helping them acquire the basic skills to learn, and thus providing the basis for lifelong learning. In this course, students were assessed at regular intervals. Since it has been found that a combination of online quizzes and tests work best to facilitate students' mastery of course material assigned (Mantyla and Woods, 2001), students were encouraged to submit assignments via email, and by actively completing online quizzes and tests. At the conclusion of the course, students presented an electronic version of their research paper, along with submitting a traditional hard copy. The assessment criteria for this course are found in Table 1. 
Bose An E-Learning Experience:

A written analysis based on my experience with primary school teachers in an e-Learning pilot project

Table 1. Assessment Criteria for "Issues and Trends in Early Childhood Education"

\begin{tabular}{||c||c||}
\hline Assignments/Tests & $30 \%$ \\
\hline \hline Presentations/Discussions & $20 \%$ \\
\hline \hline Research Paper & $50 \%$ \\
\hline \hline Total & $100 \%$ \\
\hline \hline
\end{tabular}

\section{Course Outcome}

Most of the desired objectives of this pilot project were achieved. A blended, mixed-mode course was provided with a balance between content and process. It offered students a student-centred, active, open, and life long teaching/ learning environment. The main focus was to maximize student productivity, knowledge acquisition, skills augmentation, as well as facilitate the development of personal and professional abilities (Arizona Faculties Council, 2000). The adoption of this process implied active involvement on the part of students, and the integration of academics with the students' total development. Students performed quite well in this course, and indicated that "initially they felt it was imposed on them, but later they found it's better than reading a book as you are not aware that you are learning, and actually they are learning more things at once." In sum, two students achieved a final "A" grade, two achieved a "B" grade, and one managed a "C+" (but this was primarily due to personal problems that prevented this particular student's participation in some of the quizzes, presentations, and discussions). Students were engaged in active research of content materials, provided on the WebCT platform. Students made revealing comments like: "Now I know how to find information, my research competence increased." They enjoyed the course and found this approach to be educative, informative, and a facilitator of research skills. Students selected and researched the topic of their research paper independently. They discovered the Internet to be an "eye-opener," offering comments like: "I can find information, bring it home, and evaluate in context of Botswana, and can see from the current information that early childhood education is not done properly in Botswana.”

During this course, students enhanced their basic computing skills. Students who could not hold the mouse prior to the course, could later access the materials on the class website, take active part in the discussion forum, send and receive emails, type documents, attach files/ documents to emails, engage in online quizzes and tests, and copy information to disks for later use and archiving. One student reported: "Normally I would pay somebody to type assignments for me and now I did it on my own, slowly, but I did it." Another student said: "We were computer illiterate at the beginning and learned a lot now." In sum, students assessed themselves as "Computer Illiterate" prior to the course, and as "Good" in computing skills by course completion.

The design of the course and the architecture of Web allowed the course content to be accessible from any computer anywhere, so as long as it was connected to the Internet and the user assigned a requisite user account and password. All that was required for students to access and engage in the course was access to WebCT enabled computers and an Internet connection. In reality, however, external limitations did not allow student access to computer and Internet outside the University of Botswana. Access to computers, let alone to an Internet connection, was absent in 
Bose An E-Learning Experience:

A written analysis based on my experience with primary school teachers in an e-Learning pilot project

Botswana's primary schools system (the students' place of employment). Cyber Café or public Internet outlets, which were often not locally available, were also exorbitantly costly, thereby creating significant barriers to education based not on access to technology, but on individual students' economic circumstances.

There was also an internal problem within the University. Students encountered limited access to computers in good working condition outside the SMART classroom. Thus, students could access the course materials, anytime, in the SMART classroom only, a condition that placed constraints of anywhere, anytime learning. Another problem was the access to Internet was inconsistent, and in many cases the bandwidth so slow that many webpages could not be downloaded. This finding was not surprising, however, as Internet penetration in Botswana is currently extremely low.

The most important outcome of our endeavour is that course and content quality is now standardised for this particular e-Learning package. As such, it is felt that a relatively new instructor will be able to deliver this particular e-Learning course without experiencing any major problems. Based on this e-Learning experience, the author also feels that it would be feasible to offer the same course much in the same way next year. But in order to design, develop, and deliver another similar e-Learning course, the author will need the same level of technical support and infrastructure that was available to design "Issues and Trends in Early Childhood Education." In other words, it was the author's experience that it takes substantial time and effort to design and administer an e-Learning course such as the one described. As Mantyla and Woods (2001) correctly stated: "Whether you are developing the course, reading a Web-based article, doing an assignment, or grading a project, it will take twice as long as you think. Although there are many times when technology can be a time saver, at least in the beginning technology can be a time drainer” (p. 330).

\section{Conclusion}

The quality of the e-Learning course "Issues and Trends in Early Childhood Education" was standardised using e-Learning approaches. Most pilot project objectives were achieved. The author (course instructor) found it feasible to design and deliver a mixed-mode, blended, flexitime, student centred course, which in turn provided students with the basic course contents, facilitated the development of research skills empowered them with basic computing skills, and, more significantly, provided them the basis for lifelong learning. The author is of the view that a step-by-step approach with student-oriented-active learning, designed to encourage students to explore information and materials available on a wider spectrum (e.g., Internet access), and provide a basis for their active participation in collaborative life-long teaching/ learning processes, would enable them to reap the real benefits of an e-Learning course. The author hopes that this approach may be one day popularised in the region. It is important to remember, however, e-Learning requires planning, which is especially important for courses reliant on a particular technology (Mantyla and Woods, 2001). The author hopes that for the benefit of its entire population, the Government of Botswana will adequately plan for greater Internet connectivity and increase computer and Internet access accordingly. By increasing access to technology, only then will the people of Botswana become truly engaged and thus competitive in today's global economy. 
Bose An E-Learning Experience:

A written analysis based on my experience with primary school teachers in an e-Learning pilot project

\section{References}

Arizona Faculties Council (AFC) (2002). Definition of Learner-Centered Education. Retrieved June 11, 2003 from: http://www.abor.asu.edu/4_special_programs/lce/afcdefined_lce.htm

Botswana Presidential Task Group (1997). Vision 2016: Towards Prosperity for All-Long Term Vision For Botswana.

Cook, J., and Cook, L. (1998). How technology enhances the quality of Student Centered Learning. Quality Progress 31(7), 59 - 63.

Jolliffe, J., Ritter, J., and Stevens, D. (2001). The Online Handbook: Developing and using Webbased learning. London: Kogan Page.

Horton, W. (2001). Leading e-Learning. American Society for Training and Development. Retrieved May 16, 2003 from: http://www.elearninggurus.com/articles.html

Internet Time Group (2003). How People Learn. Retrieved June 18, 2003 from: http://www.internettime.com/Learning/How\%20People\%20Learn.htm

Lynch, M. (2002). The Online Educator: A Guide to creating the virtual classroom. London: Routledge Falmer.

Mantyla, K., and Woods, J. A. (2001). The 2001/2002 ASTD Distance Learning Yearbook. New York: McGraw-Hill.

Organization for Economic Cooperation and Development (OECD) (2001). E-Learning: The Partnership Challenge. Paris: Centre for Educational Research and Innovation.

Schank, R. C. (2002). Designing World-Class e-Learning: How IBM, GE, Harvard Business School, and Columbia University are succeeding at e-learning. New York: McGraw-Hill.

Siemens, G. (2002). Instructional design in elearning. Elearnspace: Everything elearning. Retrieved June13, 2003 from: http://www.elearnspace.org/Articles/InstructionalDesign.htm

Stephenson, J. (2001). Teaching and Learning Online: Pedagogies for New Technologies. London: Kogan Page.

Syrtis.com (n.d.). Discover a New World of Instructional Solutions. Syracuse University Continuation Education. Retrieved June 29, 2003 from: www.Syritis.com

eLearning.com (2002). eLearning. Retrieved on June 18, 2003 from: http://www.learnativity.com/elearning.html 
Wheeler, H. (2003). C-MODE Pedagogy: Computer-Mediated Online and Distant Education Constructional English. On the Horizon. University of North Carolina and MCB University Press: Retrieved on September, 17, 2003 from:

http://horizon.unc.edu/projects/monograph/K12/edited/Wheeler.asp

Thurab-Nkhosi, D. (2003). WS1 Educational Principles of eLearning. University of Botswana, WebCT. Retrieved May 28, 2003 from:

http://webct.ub.bw:8900/SCRIPT/EDT118/scripts/serve_home

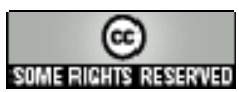

